\title{
Food allergen avoidance: risk assessment for life
}

\author{
M. Hazel Gowland \\ Allergy Action*, 23 Charmouth Road, St Albans AL1 4RS, UK
}

\begin{abstract}
The skills and knowledge required to carry out food allergen avoidance are becoming increasingly sophisticated. It is not enough to know the names of a handful of dishes which contain a known allergen as an ingredient. Many lifestyles now depend on food prepared away from the home. New product development has introduced a wide range of ingredients and dishes which are labour saving, exciting and innovative. Product traceability now depends on advanced technological support as it struggles to keep up with foods manufactured, prepared and served in ever more complex circumstances. Consumers are now faced with 'a jungle of choices'. However, those individuals who need to avoid a known allergen, particularly in trace quantities, often find that the food choice deemed suitable is poor, and the information available inadequate or even dangerously misleading. There are two important groups for whom this situation is a major concern. Thousands of families with young children are forced to live with the possibility that everyday foods may be contaminated by a known allergen which could kill in minutes. They live on their nerves, reading every packet and resorting to hyperprotective childcare and vigilance. In addition, the youngest independent consumers, teenagers and those in their twenties, may have little first-hand experience of food preparation. They may be ill-equipped in food-allergen risk assessment. Sadly, those who die from anaphylaxis or allergen-triggered asthma are often in this age-group. Current initiatives to support consumers at risk include a recognised standard for manufacturers seeking to eliminate an allergen from their production, and the integration of food allergy into training for caterers and food standards enforcement professionals.
\end{abstract}

Food allergy: Allergen avoidance: Risk assessment: Anaphylaxis

In November 1960, when I was 14 months old, my father gave me a tiny amount of peanut butter on bread. Within minutes my face swelled up and my eyes became tiny slits. The doctor was called and I was given an injection. Very slowly, the swelling went down and I made a full recovery. My parents recollect that they never knew what was in the injection, but that these very dangerous symptoms seemed to have been triggered by the tiniest quantity of peanut butter. This food was relatively novel in the UK in 1960. For those in the population who had lived through the Second World War and who were on the lookout for alternative protein sources, it represented a nutritious savoury spread, an innovation from the USA closely linked to rock-'n'-roll and all the latest transatlantic trends. However, it wasn't that common, and my parents were fairly relaxed about bringing me up to avoid it.

As a child, I tried other foods, including Grandma's famous 'tombstone trifle'. She always put almond pieces at $90^{\circ}$ in the custard topping, and we quickly discovered that just picking them out was not enough to prevent me from getting a swollen tingly mouth, streaming eyes and severe asthma. Every party or family occasion brought mixed feelings; the usual enthusiasm and excitement, but also an underlying anxiety that I might have an asthma attack, or suffer nausea and vomiting. Typically, I also had eczema which flared up when I was hot or excited, and was exacerbated by rich foods.

At that time, I was the only child we had ever heard of who had suffered such symptoms in response to nuts and peanuts. Indeed, it soon became a bit of a joke, a child called Hazel who was allergic to nuts. Thankfully, my parents adopted a matter-of-fact approach, training me to identify and avoid nuts and peanuts from a very early age and to carry out my own risk assessment.

Of course, it was easier then than it is now. Like many of her contemporaries, my grandmother was a most imaginative and talented home cook who had lived through two world wars and rationing, loved food, and was able to 
turn the smallest quantity of the most unlikely ingredient into a tasty and healthy dish. We ate foods which we understood. Most individuals could identify the main ingredients in a wide range of home-cooked dishes, and would be able to tell me that coronation chicken or a cake with marzipan contained almonds. I soon learned the names of dishes with nuts as a key ingredient in the recipe, and discovered that avoiding them was relatively simple.

At the age of 18 years, I then ate a caramel chocolate. I was well aware that some of the chocolates in the selection were nutty, and usually chose the soft-centres, strawberry or coffee creams. I had eaten the chocolate-covered caramel before, but this time I knew very quickly that I was in trouble. My father took me to the doctor's house, and I suffered a full allergic collapse (anaphylaxis) within $35 \mathrm{~min}$. After I had been stabilised with adrenaline and corticosteroid injections, I was able to return home.

We made some enquiries to find out why this non-nutty chocolate should have caused such severe symptoms. The milk-chocolate coating contained a small quantity of rework, i.e. recycled chocolate, removed from sub-standard product and mixed back into production at an earlier stage. The rework made up about $1 \%$ of the chocolate on that batch.

When I left home at 19 years of age, I was advised to carry an adrenaline inhaler and to wear a medical identity bracelet. At university, and then whilst working and studying abroad, I made sure that enough friends and colleagues were aware of my allergy, and that I might need help in an emergency. I suffered occasional reactions; symptoms which varied enormously from one episode to another, sometimes a swollen tongue or lips, sometimes a body rash (urticaria) and sometimes severe asthma, but I never needed an overnight hospital stay. Using inhaled and then injectable adrenaline and finely-honed allergen avoidance skills, I have managed to stay alive.

Now, 40 years later, life with a potentially life-threatening allergy is very different. Of course, the same type of individual is at risk; typically a child in an atopic family, in which they and their siblings may suffer from asthma, eczema, hay fever and other allergic conditions. More of the population are familiar with life-threatening allergies, particularly to nuts and peanuts. The Anaphylaxis Campaign (a national charity founded by David Reading in 1994) supports those individuals at greatest risk by investigating and providing reliable information, as well as through local or regional groups, meetings and workshops. These activities in turn lead to competent and confident management of allergic symptoms.

However, life with an allergy is not easier. Whilst improved medication has contributed to a better quality of life for some individuals, particularly through the use of preventer inhalers for asthma, allergy-related symptoms continue to restrict social activities and excursions for many more. Improved public awareness may mean that allergic conditions are more widely known about, but not necessarily better understood.

It is estimated that between 0.5 and $1 \%$ of the UK population may suffer allergic symptoms which could be life-threatening, and yet there are fewer than a handful of qualified allergy consultants available to treat them. The demand for referrals for specialist allergy care is now overwhelming; ask any general practitioner. The package of patient care required is relatively simple in most cases, and usually involves a full assessment of family background and symptoms, leading to a diagnosis which may involve skin or blood tests, competent advice on allergen avoidance and (when appropriate) an emergency care plan.

A parent who suspects that their young child may be at risk of allergic symptoms may well be told to 'wait and see'. A general practitioner may consider a child too young to assess, and too small to undergo a standard diagnosis. In practice this situation means that a large number of parents of babies and very young children live in the constant fear that their child may be at risk, but can do little in the short term except avoid the suspected allergen(s).

This approach is easier in theory than in practice. Many young children have symptoms which could be due to a food allergy, allergen-induced asthma or a food intolerance. They could also be due to a number of other childhood conditions, so that even parents and carers who see the child every day can find them hard to read. The most important and timeconsuming activity is monitoring the foods to be eaten by small children who have been advised to avoid a particular allergen (often nuts, peanuts and seeds, but also fish, eggs, cow's milk etc.).

Sadly, living at risk of a possible severe allergic reaction is not that simple. It is accepted amongst families of allergy sufferers that such vigilance is an enormous source of stress, which impacts on and beyond the immediate family. Parents who feel unable to trust a third party to care for their allergic child may defer or abandon plans to return to employment, causing an unexpected reduction in the family's income. They may feel that they should accompany their child to every party and on every trip, even when the child would normally manage very well without them. There is often an enormous burden of anxiety and guilt within the family, which leads to arguments and accusations of inadequate vigilance between parents and also with grandparents and others.

As one parent of an allergic 5 year old wrote, 'He can't understand how much danger he's in; ... All he knows is that he's singled out, he's different and that his mum and dad worry about him more than is good for them' (Weale, 2000).

The British Nutrition Foundation (2001) recently developed a Food Safety CD Rom for primary teachers in training across the UK. This resource included a baseline assessment and interviews with student teachers. The information indicated that food allergy was poorly understood by most trainees, but that nearly two-thirds of them identified it as the key food safety topic which they would need to include in their work with children in schools.

Recent research in Canada involved a study of the psychological burden of peanut allergy as perceived by adults with peanut allergy and the parents of peanut-allergic children (Primeau et al. 2000). The quality of life and family relationships of those with peanut allergy were compared with those of individuals with a rheumatological disease. Results indicated that the peanut-allergic children suffered substantially more disruption in their daily activities, and the report concluded that 'accurate diagnosis of peanut allergy is essential'. The authors also state, 'We hope to motivate 
food industries to offer more 'peanut free' products to decrease the dietary restrictions of these patients while minimizing their potential for accidental ingestion'.

A substantial amount of time is taken to carry out ordinary shopping and food preparation, and it is even more stressful because any mistake or misreading of a label means that a life is at risk. In this age of choice, families with allergy sufferers (at least one in 100) have far fewer choices. They cannot eat out when or where they choose, buy the ever-increasing range of exotic takeaways or snacks on the market, or take holidays without planning carefully how they will avoid killer food allergens.

Many families report that the most important obstacle which prevents them leading a normal life is the widespread use of 'allergen traces' labelling on pre-packed foods, particularly those aimed at or widely consumed by children, and everyday staples (bread, cereals and ordinary biscuits). They cannot understand why these foods may be contaminated by minority ingredients such as nuts, peanuts and sesame.

In a recent letter to Lancet (McCabe et al. 2001), Accident and Emergency doctors in Swansea described a research project in which they inspected 630 products (cereals, biscuits and confectionery) in four major supermarkets. Of all the products examined, $15 \%$ contained nuts as a declared ingredient, $25 \%$ appeared completely nut free and $60 \%$ carried some kind of nut contamination warning. These findings might suggest that of a sample of twenty UK cereals, biscuits and confectionery, three would contain nuts deliberately, five would appear free from nuts and twelve would have some nut contamination risk. From the nutallergic consumer's viewpoint, instead of a choice of seventeen products of twenty (which did not have nuts as an ingredient), they could choose from only five.

Another issue is the quality and legibility of the allergenrisk labelling. In spite of practical guidance from industry working groups, some major UK food manufacturers and retailers still fail to communicate the allergen risk on their products effectively. Common problems include tiny fonts (so you need your other glasses!), information hidden under a flap (so you need two hands to find it), shiny paper or ink, often in illegible colour combinations, with allergen-risk information printed away from the ingredients list.

If the manufacturer has adhered to industry guidelines, and the product carries a measured and recorded risk of allergen cross-contamination, this information is potentially life-saving. Even on a tiny packet of ten cigarettes, the health warning is on the front and back panels, in capitals, in a legible font, in a set format. It must be remembered that its purpose is to prevent an individual over 16 years of age curtailing their life by days, months or years at some unknown date in the future. Allergen-risk information is there to stop both children and adults from dying in the next minutes or hours. If it represents a real risk, it must be easy to find, clear and legible.

Whilst parents live on their nerves, and young children lead a restricted lifestyle, there is one important consumer group which often ignores allergen-risk information. Teenagers and young adults attending the Anaphylaxis Campaign's workshops report that they take no notice of 'allergen traces' labelling. They stubbornly refuse to examine ingredient labels, some believing that manufacturers are only using them to 'cover their backs'.

Sadly, individuals within this age-group are far more likely to die from a severe allergic reaction (anaphylaxis) or allergen-triggered asthma. The following information was collected from press sources as well as post-mortem and inquest information, and describes tragic events affecting mainly young adults.

Luisa Dennis died in December 2000 after eating bread which contained walnuts. She knew she was allergic to nuts, but did not expect to find them in the bread or notice them on the menu. The coroner said, 'It is perfectly natural that she did not look at the menu when the bread was being ordered.' (Knapman, 2001). She was 28 years old.

Nicola Ratcliffe was a first-year student at Durham University, apparently living away from home for the first time. She ate an Indian meal in January 2000 and although she knew she was allergic, she had left her Epipen (emergency injectable adrenaline) in her room. She died aged 18 years.

Ross Baillie was a national champion track athlete. After a training session in Bath in June 1999 he asked for a chicken sandwich. The sandwich contained 'coronation chicken' in which nuts may be used as a deliberate ingredient. He died aged 21 years.

Laura Thrasher was 19 years old and on her second day at St Catharine's College, Cambridge in October 1998. The menu at the matriculation dinner listed 'strawberry shortbread on a red fruit sauce'. The shortbread contained undeclared nuts. Laura politely sat through the cheese and biscuits and coffee before collapsing. Her life support was turned off after $3 \mathrm{~d}$.

Louise Westlake was served bread containing walnut butter at a hotel dinner in Manchester in December 1995. She knew she was allergic to nuts, but did not expect to find walnuts in the butter. She was in her mid-twenties.

Sarah Reading was served a slice of lemon meringue pie in the restaurant of a well-known chain store. Unknown to her, the dessert contained peanuts. She collapsed and died in October 1993.

Another story with a happier outcome was that of Harriet Rowlandson who was 18 years old and working as a waitress at the Farnborough Air Show in September 1998. She knew she had a nut allergy, but ate a fruit pastry tart with hidden nuts in the base. It seems that she survived because paramedics were on hand to treat her.

Whilst the Anaphylaxis Campaign has also received reports of allergic reactions suffered by younger children, these tragic stories demonstrate very clearly that teenagers and young adults are at much higher risk, particularly when eating out. Recent research by Pumphrey (2000) indicates that $76 \%$ of food allergy-related deaths followed the consumption of food away from the home. Often, the allergen was a deliberate ingredient, but was not identified on the menu or label.

Since 1994 there have been a number of initiatives to improve awareness and understanding of potentially fatal food allergies amongst food-service professionals. One of the earliest initiatives was to include the subject in the range of all National Vocational Qualification and Scottish Vocational Qualification food units (Hospitality Training 
Foundation, 1994). In 1997, the government's 'Be allergy aware' information campaign involved the distribution of posters and leaflets to food-service businesses across the UK (Ministry of Agriculture, Fisheries and Food, 1997; current information is available from UK Food Standards Agency). Some colleges and businesses involved in the professional training of chefs and service personnel have addressed allergy in their courses, but there is still much to be done. In the words of a recent editorial in Caterer and Hotelkeeper, 'It is high time that food allergy awareness was added to every training programme across the hospitality industry.' (Caterer and Hotelkeeper, 2000; see also Huddart, 2000)

Apart from their professional training, catering businesses are also required to implement food hygiene and safety standards which are monitored by environmental health officers. A recent research project carried out in Northern Ireland indicated that of thirty-seven environmental health officers questioned, only six included the control of nuts and peanuts in their assessment of hazard analysis systems in place in food-service businesses (Leitch et al. 2000). Only one of these six had received formal hazard analysis training in the control of nuts and peanuts during their primary professional training. The project report concluded by proposing 'coordinated, formal, pre and/or in service training of EHOs (environmental health officers) in food allergen control guidance into hazard analysis guidance documents a) supplied to the environmental health profession and b) circulated more widely within the food production, processing and service industries.' Environmental health professionals are certainly best placed to inform and influence the smaller businesses (ethnic restaurants and takeaways, sandwich bars etc.) which represent the greatest risk to allergy sufferers.

As a general rule, food manufacturers, particularly in mechanised modern food factories, should adopt a policy of 'keeping the allergen in'; containing it and protecting other production from any cross-contact with it. In the medium term to long term, segregated production of foods containing recognised allergens is the only solution, and any manufacturer seeking to achieve this solution merits endorsement and recognition. There has already been some interest in developing a recognised industry standard for allergen elimination in food production which could be integrated into the hazard analysis and critical control points and objectively assessed through normal third party or customer audits. This approach should involve the whole business, impacting on product development and strategic planning. An assessment of the business risk might also indicate an economic case for segregation.

This policy will be of major benefit to the many thousands of allergy sufferers and all those who share their food, who will benefit from a wider and fairer choice of ordinary foods without 'traces' labels. It will also make life a lot easier for catering staff for whom every 'traces' label raises so many dilemmas. How can they pass that information to the customer further down the line? It is reasonable to flag nuts (for example) on a menu when they are used deliberately as a key ingredient, but how do you tell customers that an individual flavour carrier, or pre-packed sauce ingredient carries some trace contamination risk?
In a parliamentary debate in June 1999, it was pointed out that food businesses which sell a product containing an undeclared genetically-modified ingredient may be liable to a fine of $£ 5000$ per item sold (UK Government, 1999). This legislation was compared with the current absence of any legal requirement to provide details of ingredients in foods sold loose or in catering situations; both situations in which allergen-risk information is often very hard to obtain. (The UK Food Standards Agency is now examining ways to make such information more easily available.) There may be many more opportunities for cross-contamination which cannot be controlled as easily. Allergy sufferers need to be made aware that the risk of accidental cross-contamination in such circumstances (salad bars, in-store bakeries, dessert trolleys) is much greater; something which is often difficult to explain, particularly to teenagers and young adults. Fortunately, many caterers are already adopting a policy to 'keep the allergen out', particularly when feeding children.

As a general rule, food-allergen labelling should fall into three categories:

1. contains (allergen); when the allergen is used deliberately as an essential part of the recipe;

2. may contain traces of (allergen); only as a short-term measure following comprehensive and committed hazard analysis and critical control points or risk assessment;

3. free from (allergen); can be helpful on foods which have an obvious connection with the allergen, (particularly on products such as confectionery, cereals, breads, biscuits which might otherwise have been in contact with nuts, peanuts and seeds).

Thus, 40 years later, life is very different. We have far more information about what we eat, but don't really understand our food as well as my grandmother did. In a recent Channel 4 television programme (Fulcrum Productions Ltd, 2000), a family with teenage children were asked to manage for 1 week without shopping at a supermarket. They usually ate a wide range of pre-packed and pre-prepared foods, but found that they were poorly equipped to cook from basic ingredients. Not only did they lack the skills and experience to prepare the food, but they had very little idea of what should be included in standard recipes.

As Shirley Conran (1975) said, 'Life is too short to stuff a mushroom'. In fact it could be even shorter if you don't assess food risks properly. In a world full of the most interesting and labour-saving food choices, allergy sufferers are one group who take their lives in their hands every time they make a food choice. A seriously nut-allergic customer cannot afford the luxury of choosing meat which has been pedigree-bred, organically-fed or humanely-killed, if it has been cut with the same knife as the nutty stuffing. Sandwich bars, local bakeries, takeaways and ready meals can represent a very real risk, and yet these sources represent a key food supply for individuals with more disposable income and busy working lives.

The following initiatives would provide support for all food professionals trying to achieve a reduction in the 
allergen risk and an improvement in the food choices for many thousands of the population:

a recognised food production standard for the elimination of a named allergen. This initiative would assist the increasing number of manufacturers committed to 'allergen-free' production, who dedicate much time and money to implementing practical measures, and deserve credit for their efforts. The standard would be objectively and independently audited and maintained. It would enable the removal of 'traces' labelling and improve the quality of life, not only for allergy sufferers, but for all those who share their food, and also for food-service professionals who need to rely on ingredients free from particular allergens;

the practical integration of food allergy information into all primary professional training for chefs, caterers and all those who prepare food for the public;

an initiative to include allergen management in food hygiene controls (hazard analysis and critical control points) for all food businesses. In practice this initiative would involve Environmental Health and Trading Standards professionals who would undergo formal and recognised training and be supported by nationallyavailable background information and materials.

Individuals with allergies are a substantial minority, and growing in number. They expect as wide a range of food choices as possible, starting with a sensible choice of everyday foods without any risk of cross-contamination from recognised allergens. They expect to be able to enjoy parties, treats and luxuries without worrying. Eventually, they would like to feel free to eat out, knowing that restaurant staff will be able to handle their requests with confidence and competence.

\section{References}

British Nutrition Foundation (2001) Teaching Food Safety CD Rom. London: British Nutrition Foundation.

Caterer and Hotelkeeper (2000) Editorial. Caterer and Hotelkeeper 14 September issue, 19.

Conran S (1975) Superwoman. London: Sidgwick and Jackson.

Fulcrum Productions Ltd (2000) Can You Live Without ... Supermarkets? Channel Four Television Documentary, 20 October. London: Fulcrum Productions Ltd.

Hospitality Training Foundation (1994) Occupational Standards National Vocational Qualifications/Scottish Vocational Qualifications for Chefs and Foodservice Staff from January 1995. London: Hospitality Training Foundation.

Huddart G (2000) Hidden killers. Caterer and Hotelkeeper 14 September issue, 50-54.

Knapman P (2001) Nut allergy tragedy after Café Flo meal. Caterer and Hotelkeeper 22 March issue, 16.

Leitch I, Blair L \& McDowell D (2000) Dealing with allergy. Environmental Health Journal 108, 335-339.

McCabe M, Lyons RA, Hodgson P, Griffiths G \& Jones R (2001) Correspondence. Lancet 357, 1531-1532.

Ministry of Agriculture, Fisheries and Food (1997) Be Allergy Aware. London: H.M. Stationery Office.

Primeau M-N, Kagan R, Joseph L, Lim H, Dufresne C, Duffy C, Prhcal D \& Clarke A (2000) The psychological burden of peanut allergy as perceived by adults with peanut allergy and the parents of peanut allergic children. Journal of Clinical and Experimental Allergy 30, 1135-1143.

Pumphrey RSH (2000) Lessons for the management of anaphylaxis from a study of fatal reactions. Journal of Clinical and Experimental Allergy 30, 1144-1150.

UK Government (1999) House of Commons debate for 24 June 1999. Point 43. Hansard. London: The Stationery Office.

Weale S (2000) Shell shock. The Guardian (Weekend) 24 June issue, 26-33. 